\title{
Метакогнитивный подход в диагностике трудностей психической саморегуляции студентов
}

\author{
Валентина М. Бызова“, Александра Е. Ловягина, Екатерина И. Перикова \\ Санкт-Петербургский государственный университет, г. Санкт-Петербург, Российская \\ Федерация \\ *E-mail: vbysova@mail.ru
}

\begin{abstract}
Аннотация
Ввеление. В статье изучаются основные причины затруднений психической саморегуляции на примере студенческой молодежи. Новизна исслеАования обуслов^ена комплексным поАХоАОм к систематизации отечественных и зарубежных исслеАований проблемы трудностей психической саморегуляции в аспекте метакогнитивизма.
\end{abstract}

Методы. В разделе описываются методики психологического тестирования: опросник «Стиль саморегуляции поведения» Моросановой, опросник «Самоорганизация Аеятельности» Мандриковой, опросник Хомла на определение уровня эмоционального интеммекта, Гиссенский опросник психосоматических жалоб, анкета «Трудности саморегуляции» Аовягиной. В исслеАовании приняли участие 113 стуАентов второго курса Санкт-Петербургского государственного университета в возрасте 19-22 ^ет (среАний возраст 19,5 ^ет).

Результаты. В результате проведенного исследования вылелены группы студентов, различающихся по уровню самоорганизации Аеятельности и стилей саморегуляции поведения. Выявлены и описаны трудности психической саморегуляции в выборке студенческой молодежи в ряде аспектов: «внимание - воля», «сАержанносты), «мыш^ение», «тревога - памяты». Подчеркнута роль стилей саморегуляции поведения и самоорганизации деятельности, а также умения управлять эмоциональной сорерой в эфрфективности преоАоления трудностей психической саморегуляции. ОбсужАение результатов. Метакогнитивный поАХОА, который лежит в основе анализа трудностей самоуправления, позволяет решать научно-исслеАовательские, а также прикладные залачи, связанные с совершенствованием навыков психической саморегуляции. В процессе работы наА осознанием трудностей психической саморегуляции и оценкой своих когнитивных особенностей у стуАентов актуализируются метапознание и понимание необходимости развития навыков психической саморегуляции. Полученные метакогнитивные знания способствуют алекватной самооценке, выбору наиболее эффрективных стратегий поведения и самоорганизации деятельности. 
ОБЩАЯ пСИХОлОГИЯ

\title{
КАючевые слова
}

психическая саморегуляция, метакогнитивный подход, метапознание, навыки метапознания, эмоциональный интелмект, когнитивные особенности, трудности саморегуляции, осознание трудностей, эффоективность самоуправления, самоорганизация Аеятельности

\section{Основные положения}

- субъективная оценка психической саморегуляции реализуется посредством метапознания, что позволяет объективно Аиагностировать трудности самоуправления; - развитое метапознание и алекватная оценка трудностей способствуют эфффективности психической саморегуляции;

- эорорективность преололения трудностей психической саморегуляции обуслов^ена уровнем эмоционального интелмекта и осознанием своих возможностей.

\section{Для цитирования}

Бызова В. М., Ловягина А. Е., Перикова Е. И. Метакогнитивный подход в диагностике трудностей психической саморегуляции студентов // Российский психологический журнал. 2019. Т. 16, № 2. С. 25-42. doi: 10.21702/rpj.2019.2.2

Материалы статьи получены 21.12.2018

UDC 159.955.4

doi: $10.21702 / r p j .2019 .2 .2$

\section{A Metacognitive Approach to Diagnosing Difficulties in Students' Mental Self-regulation}

\section{Valentina M. Byzova*, Aleksandra E. Lovyagina, Ekaterina I. Perikova}

Saint Petersburg State University, Saint Petersburg, Russian Federation

*Corresponding author. E-mail: vbysova@mail.ru

\begin{abstract}
Introduction. This study investigates the main reasons for difficulties in students' mental self-regulation and represents a first attempt to systematize previous research findings from the field in the context of the metacognitive approach.

Methods. The study used the following techniques of psychological testing: (a) the Style of Self-regulation of Behavior questionnaire by Morosanova, (b) the Self-organization of Activities questionnaire by Mandrikova, (c) the Emotional Intelligence Self-evaluation technique by N. Hall, (d) the Gissen Complaints Questionnaire, and (e) the Difficulties in Self-regulation questionnaire by Lovyagina. A sample of 113 second-year students of St. Petersburg State University with a mean age of 19.5 years took part in this study.
\end{abstract}


Results. The findings of this study indicate that several groups of students can be distinguished based on the levels of self-organization of activities and the styles of selfregulation of behavior. The authors identified and described the difficulties in students' mental self-regulation in (a) attention and will, (b) self-restraint, (c) thinking, and (d) anxiety and memory. The styles of self-regulation of behavior and self-organization of activities and the ability to manage the emotional sphere are important factors that can help to overcome difficulties in mental self-regulation.

Discussion. The metacognitive approach to the analysis of difficulties in self-regulation is capable of solving theoretical and practical problems related to improvement in mental self-regulation skills. Students' assessment of their own cognitive abilities and their awareness of difficulties in mental self-regulation enable their metacognition and contribute to the development of skills of mental self-regulation. Metacognitive knowledge facilitates adequate self-assessment skills and the choice of the most effective strategies of behavior and self-organization of activities.

\section{Keywords}

mental self-regulation, metacognitive approach, metacognition, metacognitive skills, emotional intelligence, cognitive abilities, difficulties in self-regulation, awareness of difficulties, effectiveness of self-regulation, self-organization of activity

\section{Highlights}

- Metacognition underlies subjective assessment of mental self-regulation, which contributes to the objective diagnosis of difficulties in self-regulation.

- Well-developed metacognition and adequate appraisal of difficulties contribute to effective mental self-regulation.

- The success in overcoming difficulties in mental self-regulation depends on the level of emotional intelligence and individuals' awareness of their own abilities.

\section{For citation}

Byzova, V. M., Lovyagina, A. E., \& Perikova, E. I. (2019). A Metacognitive Approach to Diagnosing Difficulties in Students' Mental Self-regulation. Rossiiskii psikhologicheskii zhurnal (Russian Psychological Journal), 16(2), 25-42. (in Russ.). doi: 10.21702/rpj.2019.2.2

Original manuscript received 21.12.2018

\section{Введение}

В современной науке понятие «саморегуляция» определяется как «универсальный принцип активности живых и квазиживых систем, направляемых целями или другими высшими критериями желательного» (Леонтьев, 2016, с. 19). В работах Леонтьева подчеркивается комплексный подход к изучению 
саморегуляции, которая определяется через личностный потенциал: как то, что «срабатывает, когда не удается уйти от необходимости изменений в деятельности и личности» (Леонтьев, 2016, с. 28).

Саморегуляция рассматривается как механизм целесообразной коррекции активности в движении от менее благоприятных к более благоприятным результатам. В целостной системе саморегуляции выделяют три уровня: гуморальной, нервной и психической регуляции, которые обеспечивают функционирование сложно организованных живых систем, включая человека (Дикая, 2003).

В современной отечественной и зарубежной психологии феномен психической саморегуляции изучается с различных ракурсов:

- как средство организации и реализации деятельности (Никифоров, 1985; Конопкин, 1995; Моросанова, 2001; Костин и Голиков, 2014; Прохоров, 2005);

- как приемы оптимизации психических состояний тревоги, стресса, утомления (Дикая, 2003; Garnefski \& Kraaij, 2007; Моросанова, 2012; Осницкий, 2009);

- как фактор развития личности (Kuhl, 1994a, 1994b; Carver \& Scheier, 2001; Прохоров, 2017; Первичко, 2014).

Еще один современный подход изучения саморегуляции включает данный феномен в структуру метапознания. Метапознание определяется как деятельность мониторинга и контроля своего познания, а его основная функция - как регуляция познавательного процесса с применением знаний о закономерностях когнитивных процессов и познания в целом (Gross, 2002; Garnefski, Kraaij, \& Spinhoven, 2001; Thompson \& Johnson, 2014; Файзуллаев, 1987; Kuhl \& Kazén, 1994; Martinez \& Davalos, 2016).

А. В. Карпов описывает структуру регуляторной рефлексии, включая регуляцию познавательной деятельности. Метапознание отражает способности понимать процесс обучения в широком смысле, регулировать собственные наблюдения, память и использовать языковые способности (А. А. Карпов, 2012; Карпов и Карпов, 2016; А. В. Карпов и Скитяева, 2005; А. В. Карпов, 2004).

Особое место в определении сущности психической саморегуляции занимают концепции, характеризующие данный феномен как проявление волевых процессов, как «способность человека к сознательной намеренной активности или к самодетерминации через работу во внутреннем плане» (Иванников, 2006, с. 93). Представление об обусловленности саморегуляции волей разделяют зарубежные авторы, по мнению которых саморегуляция опосредована волевой сферой человека и рассматривается в качестве контроля за действиями (Flavell, 1979; Brown, 1987).

Самооценка эффективности предполагает наличие переживаний, связанных с причинами затруднений самовоздействий. В исследуемых нами конкретных 
случаях трудности саморегуляции могут проявляться на разных уровнях: когнитивном («Трудно сконцентрировать внимание, вспомнить, сообразить, придумать что-то новое»); на эмоциональном («Сложно понять эмоции другого человека, выразить свои, вызвать нужные эмоции»); на волевом («Тяжело проявить настойчивость, выдержку, смелость»).

Изучение объективных трудностей самоуправления важно не только для конкретизации научных представлений о психической саморегуляции, но также имеет значение для повышения эффективности психологической помощи. Возможность оценить область, в которой наиболее выражены затруднения саморегуляции, позволяет адресно проводить совершенствование приемов психической саморегуляции. На основе выявления незначительных или существенных трудностей возможна оптимизация стилей саморегуляции поведения и деятельности. Некоторые трудности саморегуляции достаточно подробно изучены при различных видах аддикции в четырех сферах: чувств, самооценки, взаимоотношений, заботы о себе (Змановская, 2008). Несмотря на большое число отечественных и зарубежных исследований, до сих пор недостаточно изучены конкретные трудности психической саморегуляции, что может быть связано с отсутствием диагностического инструментария для соответствующих задач.

Целью настоящего исследования является выявление и обоснование основных причин затруднений психической саморегуляции. Исследование включает следующие эмпирические задачи:

1) апробировать анкету «Трудности саморегуляции» и описать особенности затруднений в общей выборке респондентов;

2) определить специфику модальностей трудностей саморегуляции;

3) оценить стили саморегуляции поведения, самоорганизации деятельности, психосоматические жалобы, особенности эмоционального интеллекта и определить их связь с модальностями трудностей психической саморегуляции.

Гипотезы исследования:

1. Модальности трудностей психической саморегуляции имеют специфику относительно самоорганизации и саморегуляции поведения, уровня эмоционального интеллекта и психосоматических жалоб респондентов.

2. Метакогнитивный подход в изучении трудностей саморегуляции позволяет дать прогноз об эффективности психической саморегуляции.

\section{Методы}

Использовались: анкета Ловягиной «Трудности саморегуляции»; методики, направленные на изучение различных аспектов саморегуляции: опросник «Стиль саморегуляции поведения» Моросановой, опросник 
самоорганизации деятельности Мандриковой, методика Холла на определение уровня эмоционального интеллекта, Гиссенский опросник психосоматических жалоб (Моросанова, 2012; Мандрикова, 2010; Трегубов и Бабин, 1992).

Статистическая обработка проводилась с использованием SPSS19/0. Применялись описательная статистика, корреляционный и факторный виды анализа.

Разработанная Ловягиной анкета «Трудности саморегуляции» включает 14 вопросов, предназначенных для оценки трудностей управления собой в отношении разных сфер психики: когнитивных процессов (память, мышление, внимание), эмоций, воли, функциональных аспектов (активизация и темп деятельности). Теоретическими основаниями для анкеты послужили научные представления об уровневости саморегуляции, а также положение о том, что структурные компоненты психической саморегуляции соответствуют метакогнитивным процессам (Карпов и Карпов, 2016). Субъективная оценка психической саморегуляции реализуется посредством метапознания, поэтому применение именно метакогнитивного подхода позволяет более объективно диагностировать трудности управления собой.

В исследовании приняли участие 113 студентов дневного отделения второго курса (19 юношей и 94 девушки) Санкт-Петербургского государственного университета в возрасте 19-22 лет (средний возраст 19,5 лет). Процедура исследования предполагала заполнение бумажных версий опросников в условиях учебных аудиторий. Участие в исследовании было добровольным и анонимным.

\section{Результаты}

В соответствии с целью и задачами исследования был проведен факторный анализ результатов по каждому отдельному пункту опросника, включивший 113 наблюдений. Применение метода главных компонент с ротацией факторов «Varimax» позволило получить 14 переменных и выделить 4 фактора, объясняющих 64,2% дисперсии исходной корреляционной матрицы (табл. 1). В качестве критерия значимости показателя была использована факторная нагрузка более 0,5 (KMO = 0,748, Bartlett's Test $=455,125 \mathrm{df}=91, \mathrm{p}=0,0000)$.

Из таблицы 1 можно видеть, что самый значимый первый фактор сформировали вопросы: «Не могу сконцентрироваться на том, что нужно» $(0,822)$, «Постоянно отвлекаюсь» $(0,779)$, «Трудно активизироваться, преодолеть лень, апатию» $(0,732)$, «Не могу решиться и начать действовать» $(0,563)$, «Не могу проявить настойчивость и довести дело до конца» $(0,564)$. Первый фактор объединяет трудности в таких аспектах саморегуляции, как внимание и воля. 


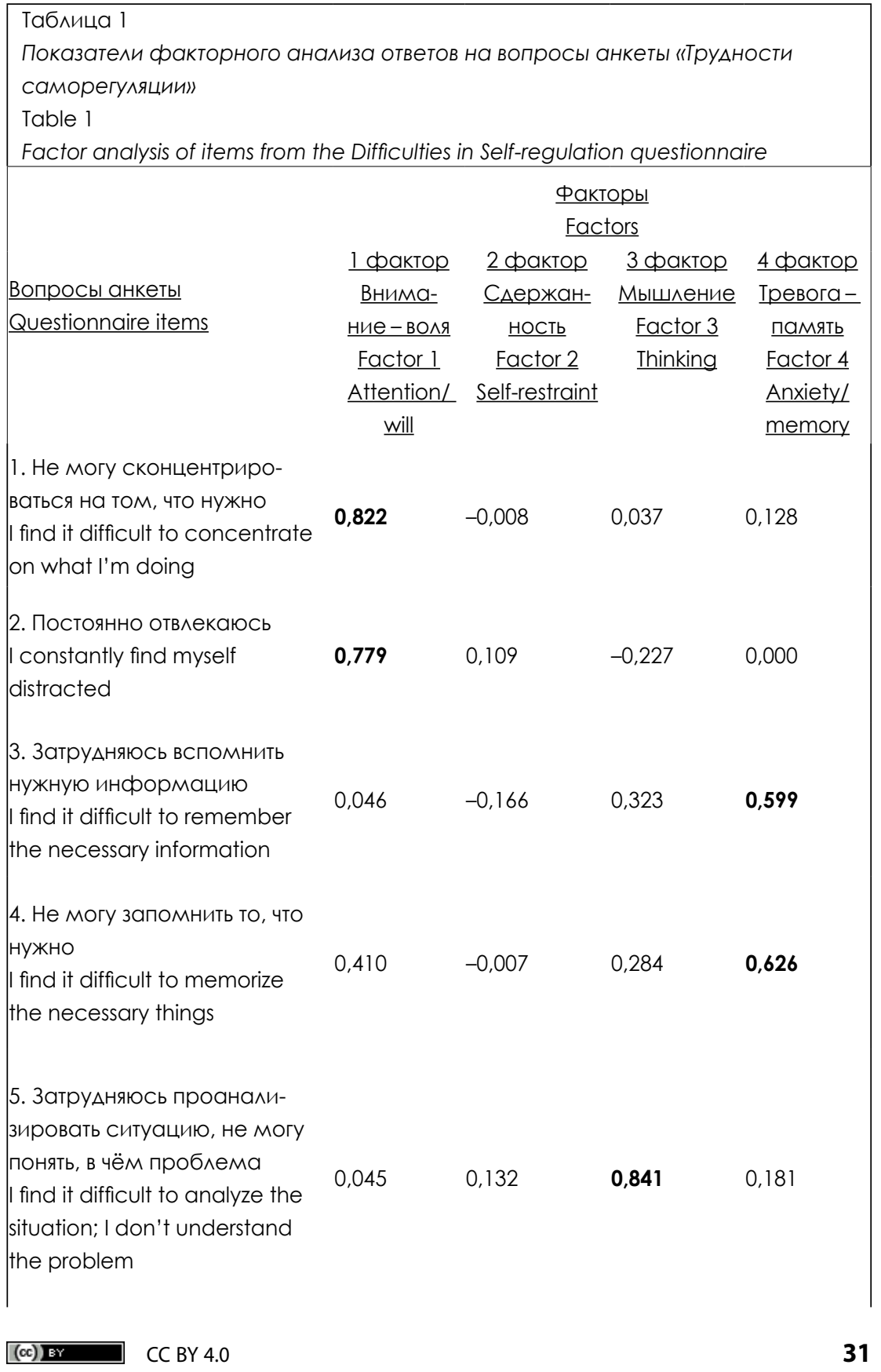




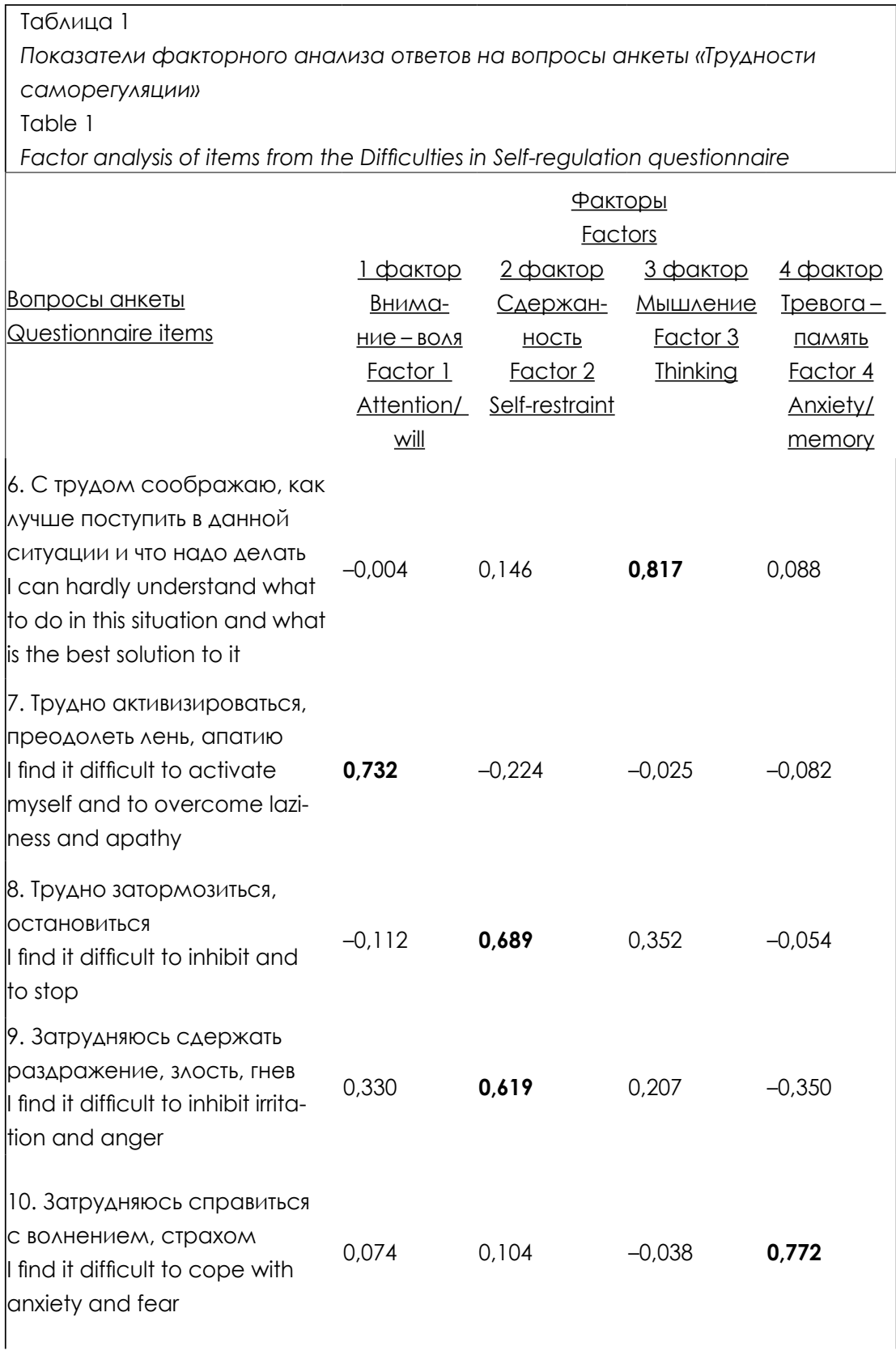




\begin{tabular}{|c|c|c|c|c|}
\hline $\begin{array}{l}\text { Таблица } 1 \\
\text { Показатели фракторного ан } \\
\text { саморегуляции» } \\
\text { Table } 1 \\
\text { Factor analysis of items from } t\end{array}$ & ииза ответов & $\begin{array}{l}\text { на вопросы с } \\
\text { in Self-regulatic }\end{array}$ & $\begin{array}{l}\text { анкеты «трудн } \\
\text { on questionnc }\end{array}$ & ности \\
\hline & & $\frac{\Phi \mathrm{ak}}{\underline{\mathrm{Fac}}}$ & $\begin{array}{l}\text { торы } \\
\text { tors }\end{array}$ & \\
\hline & 1 dрактор & 2 opaктор & 3 dрактор & 4 орактор \\
\hline Вопросы анкеты & Внима- & САержан- & Мышление & Тревога- \\
\hline Questionnaire items & Hие-воля & HOCTb & Factor 3 & память \\
\hline & Factor 1 & Factor 2 & Thinking & Factor 4 \\
\hline & $\frac{\text { Attention/ }}{\underline{\text { will }}}$ & $\underline{\text { Self-restraint }}$ & & $\begin{array}{l}\text { Anxiety/ } \\
\text { memory }\end{array}$ \\
\hline 11. Трудно Аействовать энер- & & & & \\
\hline $\begin{array}{l}\text { гичнее, активнее } \\
\text { I find it difficult to act more } \\
\text { vigorously and actively }\end{array}$ & 0,472 & $-0,465$ & 0,304 & 0,316 \\
\hline 12. Трудно Аействовать меА- & & & & \\
\hline ^еннее, спокойнее & & & & \\
\hline $\begin{array}{l}\text { I find it difficult to act more } \\
\text { slowly and calmer }\end{array}$ & $-0,116$ & 0,804 & 0,016 & 0,264 \\
\hline $\begin{array}{l}\text { 13. Не могу решиться и на- } \\
\text { 4ать действовать }\end{array}$ & & & & \\
\hline $\begin{array}{l}\text { I hesitate and find it difficult to } \\
\text { start doing things }\end{array}$ & 0,563 & $-0,358$ & 0,243 & 0,205 \\
\hline $\begin{array}{l}\text { 14. Не могу проявить на- } \\
\text { стойчивость и Аовести Ае^о }\end{array}$ & & & & \\
\hline $\begin{array}{l}\text { АО конца } \\
\text { I find it difficult to be persistent } \\
\text { and to bring things to a close }\end{array}$ & 0,564 & 0,071 & 0,138 & 0,234 \\
\hline
\end{tabular}

Второй фактор включил вопросы: «Трудно действовать медленнее, спокойнее» $(0,804)$, «Трудно затормозиться, остановиться» $(0,689)$, «Затрудняюсь сдержать раздражение, злость, гнев» $(0,619)$, которые отражают функциональный и эмоциональный аспекты саморегуляции в плане проявления сдержанности. 
Третий фактор включил вопросы, связанные с трудностями в процессе мышления: «Затрудняюсь проанализировать ситуацию, не могу понять, в чём проблема» $(0,841)$, «С трудом соображаю, как лучше поступить в данной ситуации и что надо делать» $(0,817)$.

Четвертый фактор составили вопросы: «Затрудняюсь справиться с волнением, страхом» $(0,772)$, «Не могу запомнить то, что нужно» $(0,626)$, «Затрудняюсь вспомнить нужную информацию» $(0,599)$. Примечательно, что затруднения, обусловленные тревогой, и особенности памяти оказались связаны, причем тревога первична.

Факторный анализ полученных результатов показал, что наибольшие трудности студенты испытывают в области осознанной саморегуляции, связанной с волевыми процессами и вниманием. Второе место по значимости составили трудности в сдерживании эмоций, снижении излишнего возбуждения и перехода к более спокойной работе (фактор 2). В третьем и четвергом факторах отражены трудности саморегуляции, связанные с мышлением и памятью. Описательные статистики по полученным шкалам обнаружили следующие показатели: первый фактор $\mathrm{M}=2,92 \pm 0,9 ;$ второй фрактор $\mathrm{M}=2,60 \pm 0,98$; третий фактор $\mathrm{M}=2,30 \pm 1,03 ;$ четвертый фактор $\mathrm{M}=5,2 \pm 0,83$.

Статистический анализ включил описательные статистики 24-х показателей. Были получены средние значения и стандартные отклонения индексов шкал, характеризующих параметры психической саморегуляции: «планирование» $(5,7 \pm 2,1)$, «моделирование» $(5,5 \pm 1,56)$, «программирование» $(5,89 \pm 1,7)$, «оценивание результатов» $(6,1 \pm 1,44)$, «гибкость» $(6,34 \pm 1,99)$, «общий уровень саморегуляции» $(5,23 \pm 2,13)$, «планомерность» $(17,7 \pm 8,62)$, «наличие целей» $(32,6 \pm 7,7)$, «настойчивость» $(19,02 \pm 6,13)$, «фиксация» $(19,1 \pm 5,2)$, «самоорганизация» $(10,8 \pm 4,65)$, «ориентация на настоящее» $(8,25 \pm 2,97)$, «суммарный показатель ОСД» $(107,7 \pm 18,93)$, «эмоциональная осведомленность» $(10,3 \pm 5,2)$, «управление своими эмоциями» $(9,7 \pm 6,7)$, «самомотивация» $(10,63 \pm 6,62)$, «эмпатия» $(9,46 \pm 5,3)$, «управление чужими эмоциями» $(7,99 \pm 5,2)$, «общий уровень эмоционального интеллекта» $(74,4 \pm 20,8)$, «истощение» $(8,23 \pm 4,87)$, «желудочные жалобы» $(3,16 \pm 3,1)$, «ревматический фактор» $(5,72 \pm 4,4)$, «сердечные жалобы» $(3,3 \pm 3,4)$, «давление жалоб» $(20,3 \pm 12,5)$.

По итогам корреляционного анализа обнаружены связи выявленных факторов и показателей ряда методик для оценки разных аспектов саморегуляции. Наиболее выраженный первый фактор обнаружил отрицательные связи со шкалами опросника самоорганизации деятельности Мандриковой: «гибкость» $(r=-0,214 ; p<0,010)$ и «общий уровень саморегуляции» $(r=-0,266$; $\mathrm{p}<0,005)$; со шкалой «самомотивация» опросника Холла на эмоциональный интеллект ( $r=-301 ; \mathrm{p}<0,001)$. Выявлена положительная связь с показателем «общих жалоб» Гиссенского опросника $(r=0,248, p<0,008)$. 
Второй фактор обнаружил отрицательную связь со шкалой «гибкость» $(r=-0,249 ; p<0,008)$ опросника самоорганизации деятельности.

\section{Обсуждение результатов}

Затруднения психической саморегуляции в выборке студентов обусловлены в значительной мере недостаточно выраженными характеристиками внимания и воли (фактор 1). Как известно, проявление волевых усилий (настойчивости, смелости, самообладания) способствует тому, что человек может направлять внимание на процесс деятельности и удерживать эту направленность столько, сколько нужно, не позволяя себе отвлекаться на переживания и мысли о возможных неудачах. Вытеснение негативных эмоций реализуется путем произвольного переключения внимания с образов, вызывающих эти эмоции, на контроль деятельности, поведения и психического состояния. Наши результаты вполне согласуются с представленными в литературе данными (Иванников, 2006; Мандрикова, 2010).

Объединение в один фактор трудностей сдерживания эмоций и снижения активности (фактор 2), по-видимому, объясняется особенностями нервной системы, балансом процессов возбуждения и торможения. Известно, что проявление эмоций, работоспособности и энергичности обусловлено выраженностью свойств нервной системы (Русалов, 2012). При доминировании возбуждения эмоциональное реагирование происходит бурно, эмоции настолько «захлестывают», что трудно сдержаться, действовать более спокойно и рассудительно. Полученные данные позволяют предположить, что проявление сдержанности у студентов в большей степени обусловлено особенностями нервной системы, чем развитием навыков осознанной произвольной саморегуляции.

Трудности регулирования мыслительных процессов оказались взаимосвязаны лишь между собой, но не связаны с трудностями регулирования других сфер (фактор 3). Таким образом, саморегуляция процессов мышления представляется относительно независимой от саморегуляции других проявлений психики: эмоций, активности, памяти и внимания. Возможно, что эффективность саморегуляции мышления в большей степени определяется развитостью собственно мыслительных процессов (анализа, синтеза, обобщения). Полученные данные согласуются с исследованиями нарушений саморегуляции познавательной деятельности, не связанных со снижением логических операций, а проявляющихся в невозможности поставить цель и организовать свою деятельность (Моросанова, 2012; Мандрикова, 2010).

В отличие от затруднений саморегуляции мыслительных процессов, трудности регулирования процессов памяти не только взаимосвязаны между собой, но также связаны с трудностями самоуправления состоянием тревоги 
и страха (фактор 4). Эти данные в целом согласуются с научными представлениями о взаимосвязях выраженности тревоги и страха с продуктивностью когнитивных процессов: при невысоком уровне тревоги (страха) имеет место эффект мобилизации - повышение концентрации внимания, улучшение памяти и сообразительности. Однако при высоком уровне тревоги (страха) отмечается дезорганизация - рассеянность и снижение оперативной памяти (Прохоров, 2005; Осницкий, 2009). Следует учитывать, что мнемическая деятельность (запоминание и воспроизведение) чаще всего реализуется при постановке цели запомнить какую-либо информацию. При запоминании происходит выделение запоминаемого материала от других явлений. При переживании тревоги (в ситуации неконкретной угрозы) и страха (в ситуации конкретной угрозы) когнитивные функции фокусируются на теме опасности и не могут в полной мере быть задействованы в выдвижении цели и выделении запоминаемого материала (Прохоров, 2005; Garnefski \& Kraaij, 2007).

Полученные результаты свидетельствуют о том, что увеличение трудностей регулирования направленности внимания и воли взаимосвязано со снижением гибкости в планировании и организации деятельности. Высокий уровень гибкости планирования деятельности связан с легкой переключаемостью внимания, которая детерминирована подвижностью нервных процессов (Русалов, 2012). Таким образом, высокая подвижность нервных процессов способствует переключаемости внимания и гибкости планирования, однако препятствует устойчивости внимания, планомерности и настойчивости в достижении цели. Иначе говоря, вместо достижения выбранной цели могут выдвигаться другие цели. Аналогично можно объяснить выявленные взаимосвязи между понижением гибкости планирования и увеличением трудностей в сдерживании эмоционального возбуждения (фактор 2). При высокой подвижности нервных процессов человеку легко действовать гибко и быстро менять планы, однако бывает трудно сдерживать эмоциональное возбуждение и тормозить излишнюю активность.

Взаимосвязи между трудностями саморегуляции в сфере внимания и воли и ухудшением управления своим поведением (шкала самомотивации в методике эмоционального интеллекта Холла) представляются логически обоснованными, т. к. регулирование эмоций осуществляется посредством актуализации волевых усилий и произвольного внимания. Взаимосвязи между повышением трудностей саморегуляции воли и внимания и жалобами на здоровье, очевидно, объясняются тем, что не удается блокировать тревогу и негативные переживания, связанные со здоровьем и ухудшением самочувствия.

Проведенное исследование показало, что анкета «Трудности саморегуляции» может применяться для диагностики особенностей психической саморегуляции в разных сферах: когнитивной, эмоциональной, волевой. 
В процессе работы над осознанием трудностей психической саморегуляции и оценкой своих когнитивных особенностей у студентов актуализируются метапознание, понимание необходимости развития навыков психической саморегуляции. Полученные метакогнитивные знания способствуют более адекватной самооценке, выбору наиболее эффективных стратегий поведения и самоорганизации деятельности. Метакогнитивный подход, лежащий в основе анализа трудностей самоуправления, позволяет решать не только научно-исследовательские, но и прикладные задачи, связанные с совершенствованием навыков психической саморегуляции.

В перспективе для уточнения полученных результатов необходимы исследования трудностей саморегуляции в связи с выраженностью свойств нервной системы и сформированностью регуляторных личностных свойств. Подобные исследования позволили бы определить ведущие факторы, детерминирующие трудности самоуправления. Необходимо дополнительно провести психометрические процедуры оценки валидности и надежности анкеты «Трудности саморегуляции».

\section{Выводы:}

1. Выраженность трудностей психической саморегуляции определяется невысоким уровнем эмоционального интеллекта, неумением управлять своими эмоциями в состоянии эмоционального возбуждения, особенно при переживании тревоги и страха, сопровождаемых эмоционально окрашенными жалобами на здоровье.

2. Трудности саморегуляции проявляются чаще всего в волевой и когнитивной сферах: в недостаточности волевых усилий, в низкой концентрации внимания, невысокой реализации мыслительных операций и мнемических функций.

3. Недостаточное регулирование волевых процессов и внимания обусловлено снижением общего уровня осознанной саморегуляции и инертностью регуляторных процессов.

\section{Благодарности}

Исследование выполнено при поддержке РФФИ 18-013-00256а «Эффективность метакогнитивных стратегий принятия решений в условиях неопределенности и трудных жизненных ситуаций».

\section{Acknowledgments}

This study was supported by the Russian Foundation for Basic Research (project no. 18-013-00256a, "The effectiveness of meta-cognitive strategies for decisionmaking under conditions of uncertainty and in difficult life situations"). 
ОБЩАЯ ПСИХОЛОГИЯ

\section{Литература}

Дикая Л. Г. Психическая саморегуляция функционального состояния человека (системно-деятельностный подход). М.: Изд-во Института психологии $\mathrm{PAH}, 2003.318 \mathrm{c}$.

Змановская Е. В. Теоретико-методологическое обоснование общей теории девиантности и девиантного поведения // Ученые записки СанктПетербургского государственного института психологии и социальной работы. 2008. Т. 9, № 1. С. 133-138.

Иванников В. А. Психологические механизмы волевой регуляции. СПб.: Питер, 2006. 208 c.

Карпов А. А. Взаимосвязи обучаемости и метакогнитивных качеств личности // Ярославский педагогический вестник. 2012. Т. 2, № 3. С. 228-235.

Карпов А. А., Карпов А. В. Взаимосвязь психометрического интеллекта с организацией метакогнитивных процессов и качеств личности // Психологический журнал. 2016. Т. 37, № 2. С. 69-78.

Карпов А. В. Рефлексия в структуре метакогнитивной организации субъекта // Рефлексивные процессы и управление. 2004. Т. 4, № 1. С. 99-109.

Карпов А. В., Скитяева И. М. Психология метакогнитивных процессов личности. М.: Изд-во ИП РАН, 2005. 352 с.

Конопкин О. А. Психическая саморегуляция произвольной активности человека (структурно-функциональный аспект) // Вопросы психологии. 1995. № 1. С. 5-13. Костин А. Н., Голиков Ю. Я. Организационно-процессуальный анализ психической регуляции сложной деятельности. М.: Изд-во Института психологии $\mathrm{PAH}, 2014.448 \mathrm{C}$.

Леонтьев Д. А. Саморегуляция, ресурсы и личностный потенциал // Сибирский психологический журнал. 2016. № 62. C. 18-37. DOI: 10.17223/17267080/62/3

Мандрикова Е. Ю. Разработка опросника самоорганизации деятельности (ОСД) // Психологическая диагностика. 2010. № 2. С. 59-83.

Моросанова В. И. Индивидуальный стиль саморегуляции: феномен, структура и функции в произвольной активности человека. М.: Наука, 2001. 192 с. Моросанова В. И. Психология саморегуляции. М.; СПб.: Нестор-История, 2012. 280 c.

Никифоров Г. С. Теоретические вопросы самоконтроля // Психологический журнал. 1985. Т. 6. № 5. С. 19-31.

Осницкий А. К. Регуляторный опыт, субъектная активность и самостоятельность человека. Часть 2 // Психологические исследования: электрон. науч. журн. 2009. № 6 (8). URL: http://psystudy.ru (дата обращения: 07.10.2018). Первичко Е. И. Стратегии регуляции эмоций: процессуальная модель Дж. Гросса и культурно-деятельностный подход // Национальный психологический журнал. 2014. № 4 (16). C. 13-22. DOI: $10.11621 /$ npj.2014.0402 


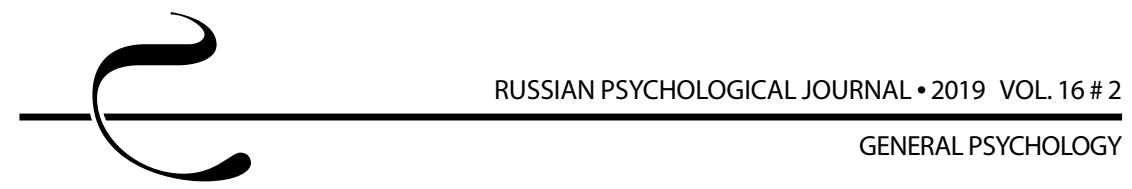

Прохоров А. О. Саморегуляция психических состояний в повседневной, обыденной жизнедеятельности человека // Психологические исследования. 2017. T. 10, № 56. C. 7. URL: http://psystudy.ru (дата обращения: 07.10.2018).

Прохоров А. О. Функциональные структуры и средства саморегуляции психических состояний // Психологический журнал. 2005. Т. 26, № 2. C. 68-80.

Русалов В. М. Темперамент в структуре индивидуальности человека. Дифференциально-психофизиологические и психологические исследования. М.: Изд-во ИП РАН, 2012. 528 с.

Трегубов И. Б., Бабин С. М. Гиссенский опросник соматических жалоб. СПб., 1992. 23 C.

Файзуллаев А. А. Мотивационная саморегуляция личности. Ташкент: Фан, 1987. $134 \mathrm{c}$.

Brown A. Metacognition, executive control, self-regulation, and other more mysterious mechanisms // Metacognition, motivation, \& understanding / F. E. Weinert, R. H. Kluwe (Eds.). Hillsdale, NJ: Lawrence Erlbaum, 1987. P. 65-116.

Carver C. S., Scheier M. F. Optimism, pessimism, and self-regulation // Optimism and pessimism: Implications for theory, research, and practice / E. C. Chang (Ed.). Washington, DC: American Psychological Association, 2001. P. 31-51.

Flavell J. H. Metacognition and cognitive monitoring: A new area of cognitivedevelopmental inquiry // American Psychologist. 1979. Vol. 34 (10). P. 906-911. DOI: $10.1037 / 0003-066 X .34 .10 .906$

Garnefski N., Kraaij V. The cognitive emotion regulation questionnaire // European Journal of Psychological Assessment. 2007. Vol. 23. P. 141-149. DOI: $10.1027 / 1015-5759.23 .3 .141$

Garnefski N., Kraaij V., Spinhoven P. Negative life events, cognitive emotion regulation, and emotional problems // Personality and Individual Differences. 2001. Vol. 30, Issue 8. P. 1311-1327. DOI: 10.1016/S0191-8869(00)00113-6

Gross J. J. Emotion regulation: affective, cognitive, and social consequences // Psychophysiology. 2002. Vol. 39, Issue 3. P. 281-291. DOI: $10.1017 /$ $\underline{\text { S0048577201393198 }}$

Kuhl J. A theory of action and state orientations //Volition and personality: Action versus state orientation / J. Kuhl, J. Beckmann (Eds.). Göttingen, Germany: Hogrefe, 1994a. P. 9-46.

Kuhl J. Action and state orientation: Psychometric properties of the action control scales (ACS-90) // Volition and personality: Action versus state orientation / J. Kuhl, J. Beckmann (Eds.). Göttingen, Germany: Hogrefe, 1994b. P. 47-59.

Kuhl J., Kazén M. Self-discrimination and memory: State orientation and false selfascription of assigned activities // Journal of Personality and Social Psychology. 1994. Vol. 66 (6). P. 1103-1115. DOI: $10.1037 / 0022-3514.66 .6 .1103$ 
Martinez S., Davalos D. Investigating metacognition, cognition and behavioral deficits of college students with acute traumatic brain injuries // Journal of American College Health. 2016. Vol. 64, Issue 5. P. 390-396. DOI: 10.1080/07448481.2016.1167057

Thompson V. A., Johnson S. C. Conflict, metacognition and analytic thinking // Thinking \& Reasoning. 2014. Vol. 20, Issue 2. P. 215-244. DOI: $\underline{10.1080 / 13546783.2013 .869763}$

\section{References}

Brown, A. (1987). Metacognition, executive control, self-regulation, and other more mysterious mechanisms. In F. E. Weinert, R. H. Kluwe (Eds.), Metacognition, motivation, \& understanding (pp. 65-116). Hillsdale, NJ: Lawrence Erlbaum.

Carver, C. S., \& Scheier, M. F. (2001). Optimism, pessimism, and self-regulation. In E. C. Chang (Ed.), Optimism and pessimism: Implications for theory, research, and practice (pp. 31-51). Washington, DC: American Psychological Association.

Dikaya, L. G. (2003). Mental self-regulation of human functional status: A system-activity approach. Moscow: Russian Academy of Sciences; Institute of Psychology. (in Russ.).

Faizullaev, A. A. (1987). Motivational self-regulation. Tashkent: Fan. (in Russ.).

Flavell, J. H. (1979). Metacognition and cognitive monitoring: A new area of cognitive-developmental inquiry. American Psychologist, 34(10), 906-911. doi: $10.1037 / 0003-066 \times .34 .10 .906$

Garnefski, N., \& Kraaij, V. (2007). The cognitive emotion regulation questionnaire. European Journal of Psychological Assessment, 23, 141-149. doi: 10.1027/1015-5759.23.3.141

Garnefski, N., Kraaij, V., \& Spinhoven, P. (2001). Negative life events, cognitive emotion regulation, and emotional problems. Personality and Individual Differences, 30(8), 1311-1327. doi: 10.1016/S0191-8869(00)00113-6

Gross, J. J. (2002). Emotion regulation: affective, cognitive, and social consequences. Psychophysiology, 39(3), 281-291. doi: 10.1017/S0048577201393198

Ivannikov, V. A. (2006). Psychological mechanisms of volitional regulation. St. Petersburg: Piter. (in Russ.).

Karpov, A. A. (2012). Interrelations between learnability and metacognitive personal traits. Yaroslavskii pedagogicheskii vestnik (Yaroslavl Pedagogical Bulletin), 2(3), 228-235. (in Russ.).

Karpov, A. V. (2004). Reflection in the structure of a subject's metacognitive organization. Refleksivnye protsessy i upravlenie (Reflexive Processes and Control), 4(1), 99-109. (in Russ.).

Karpov, A. A., \& Karpov, A. V. (2016). Interrelations between psychometric intelligence and the organization of personality traits and metacognitive processes. Psikhologicheskii zhurnal, 37(2), 69-78. (in Russ.). 


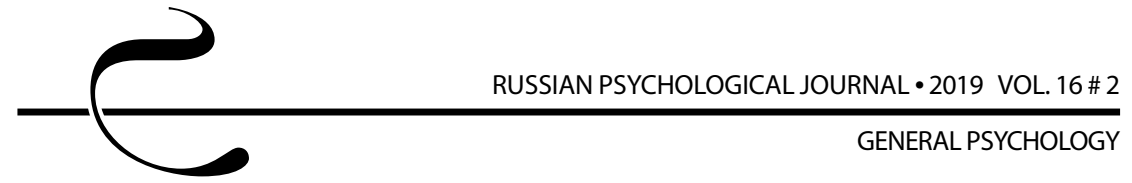

Karpov, A. V., \& Skityaeva, I. M. (2005). Psychology of personal metacognitive processes. Moscow: Russian Academy of Sciences; Institute of Psychology. (in Russ.).

Konopkin, O. A. (1995). Mental self-regulation of voluntary activity: A structuralfunctional perspective. Voprosy psikhologii, 1, 5-13. (in Russ.).

Kostin, A. N., \& Golikov, Yu. Ya. (2014). The organizational and procedural approach to the analysis of the mental regulation of complex activity. Moscow: Russian Academy of Sciences; Institute of Psychology. (in Russ.).

Kuhl, J. (1994a). A theory of action and state orientations. In J. Kuhl \& J. Beckmann (Eds.), Volition and personality: Action versus state orientation (pp. 9-46). Göttingen, Germany: Hogrefe.

Kuhl, J. (1994b). Action and state orientation: Psychometric properties of the action control scales (ACS-90). In J. Kuhl \& J. Beckmann (Eds.), Volition and personality: Action versus state orientation (pp. 47-59). Göttingen, Germany: Hogrefe.

Kuhl, J., \& Kazén, M. (1994). Self-discrimination and memory: State orientation and false self-ascription of assigned activities. Journal of Personality and Social Psychology, 66(6), 1103-1115. doi: 10.1037/0022-3514.66.6.1103

Leont'ev, D. A. (2016). Self-regulation, resources, and personal potential. Sibirskii psikhologicheskii zhurnal (Siberian Psychological Journal), 62, 18-37. doi: 10.17223/17267080/62/3 (in Russ.).

Mandrikova, E. Yu. (2010). Development of the self-organization questionnaire (SOQ). Psikhologicheskaya diagnostika (Psychological Diagnostics), 2, 59-83. (in Russ.).

Martinez, S., \& Davalos, D. (2016). Investigating metacognition, cognition and behavioral deficits of college students with acute traumatic brain injuries. Journal of American College Health, 64(5), 390-396. doi: 10.1080/07448481.2016.1167057 Morosanova, V. I. (2001). The individual style of self-regulation: The phenomenon, structure, and function in human voluntary activity. Moscow: Nauka. (in Russ.).

Morosanova, V. I. (2012). Psychology of self-regulation. Moscow; St. Petersburg: Nestor-Istoriya. (in Russ.).

Nikiforov, G. S. (1985). Theoretical issues of self-control. Psikhologicheskii zhurnal, 6(5), 19-31. (in Russ.).

Osnitskii, A. K. (2009). Regulatory experience, subjective activity, and human independence: Part 2. Psychological Studies, 6(8). Retrieved from http:// psystudy.ru (in Russ.).

Pervichko, E. I. (2014). Strategies for the regulation of emotions: J. Gross procedural model and cultural activity approach. Natsional'nyi psikhologicheskii zhurnal (National Psychological Journal), 4(16), 13-22. doi: 10.11621/npj.2014.0402 (in Russ.).

Prokhorov, A. O. (2005). Functional structures and means for self-regulation of mental states. Psikhologicheskii zhurnal, 26(2), 68-80. (in Russ.). 
Prokhorov, A. O. (2017). Self-regulation of mental states in daily, ordinary activity of the person. Psychological Studies, 10(56), p. 7. Retrieved from http:// psystudy.ru (in Russ.).

Rusalov, V. M. (2012). Temperament in the structure of human individuality: Differential psychophysiological and psychological studies. Moscow: Russian Academy of Sciences; Institute of Psychology. (in Russ.).

Thompson, V. A., \& Johnson, S. C. (2014). Conflict, metacognition and analytic thinking. Thinking \& Reasoning, 20(2), 215-244. doi: 10.1080/13546783.2013.869763 Tregubov, I. B., \& Babin, S. M. (1992). Giessen Subjective Complaints List. St. Petersburg. (in Russ.).

Zmanovskaya, E. V. (2008).Theoretical and methodological foundations for the general theory of deviance and deviant behavior. Uchenye zapiski Sankt-Peterburgskogo gosudarstvennogo instituta psikhologii i sotsial'noi raboty (Scientific Notes Journal of St. Petersburg State Institute of Psychology and Social Work), 9(1), 133-138. (in Russ.). 